\title{
Los feminismos en el laberinto de las izquierdas gobernantes en América Latina. Reflexiones inacabadas
}

Virginia VARGAS

\begin{abstract}
RESUMEN
El ensayo analiza los procesos impulsados por los gobiernos progresistas en América Latina desde el enfoque de género y acceso a derechos, enfocándose en las relaciones por ampliar la democracia, los derechos humanos y la agenda de género entre el gobierno y los movimientos feministas.
\end{abstract}

PALABRAS CLAVE: feminismo, derechos humanos, democracia, patriarcado, izquierda.

\section{Feminisms in the maze of leftist leaders in Latin America. Reflections unfinished}

\section{ABSTRACT}

The essay analyzes the processes driven by progressive governments in Latin America from a gender perspective and from human rights, focusing on relationships to expand democracy, human rights and gender agenda between the government and feminist movements.

KEYWORDS: feminism, human right, democracy, patriarchy, left wing. 


\section{La memoria}

María Elena Moyano fue asesinada por Sendero Luminoso el 15 de febrero de 1992, ametrallada y volada en mil pedazos. Fue una muerte anunciada, Sendero Luminoso la había amenazado varios meses antes, pero María Elena siguió luchando contra ellos, denunciando su presencia en los barrios, exigiendo a los partidos políticos que llegaran a un acuerdo para detener su avance. No hubo respuesta ni solidaridad, ni compromiso con nada más que su perfil y su verdad. Resultado: María Elena fue asesinada y Sendero Luminoso ganó las elecciones en el Parque Industrial de Villa El Salvador porque las izquierdas prefirieron mantener su perfil'.

A nalizar a los gobiernos "progresistas" o de "izquierda" en America Latina desde mi mirada feminista no puede ser aislada de la memoria de luchas feministas en la región desde las últimas décadas del siglo pasado. No puede tampoco ser abstraída de la subjetividad política que ha guiado mi accionar, como feminista ubicada en el amplio abanico de las "izquierdas", no solo por mi pasado de militante partidaria, sino porque estoy convencida que la definición y acción de los partidos políticos de las izquierdas no pueden pretender monopolizar un horizonte de transformación radical y democrático al que los feminismos y algunos movimientos sociales y políticos contribuyeron a alimentar en las últimas décadas.

La historia del surgimiento y expansión de los feminismos en America Latina, en la oleada de la década del setenta del siglo XX está estrechamente ligada a los partidos políticos de izquierda. De allí veníamos, allí expresábamos nuestra rebeldía, nuestro esfuerzo por cambiar el mundo. Aunque la participación de las mujeres al interior de los partidos era claramente secundaria, nuestra lucha en contra de las dictaduras y por la recuperación y ampliación de la democracia se nutria de este horizonte de transformación.

Aprendimos de manera brutal que los partidos políticos no eran nuestro espacio; si no levantábamos nuestros propios asuntos, nadie lo haría por nosotras. Nuestras primeras movilizaciones a inicios del ochenta, alrededor de una dimensión política central en las agendas feministas como los derechos sexuales y derechos reproductivos, incluyendo el aborto, marcaron el fin de esta primera etapa de luna de miel indiferenciada. De haber sido consideradas hasta ese momento como mujeres competentes, inteligentes, progresistas, que apoyábamos la lucha de los oprimidos, nos convertimos, a los ojos de la mayoría de los hombres - y de muchas mujeres - de los partidos de izquierda, en mujeres histéricas, pequeño burguesas, influenciadas

1 Vargas, Virginia. Feminismo e izquierda en el Perú: Trágicos desencuentros. En: Feminismos en América Latina. Su aporte a la política y a la democracia. UNMSM. PDTG. Flora Tristán. 2008.

\section{0/ REVISTA DESSCIOLOGGíA 26}


por ideas foráneas que buscaban dividir la unidad popular bajo la influencia de un feminismo occidental y ajeno a nuestra realidad. La autonomía recién descubierta y defendida por el movimiento feminista, fue considerada como alejamiento de la lucha real, encapsulamiento, guetización. A partir de este momento la relación con los partidos de izquierda cambió dramáticamente.

Lo más doloroso y desgastante de este período fue, sin duda, el alejarnos de las mujeres de partido que habían comenzado, casi con nosotras, su perfilamiento feminista. Ellas siguieron también su lucha. A través de la creación de comisiones femeninas en el interior de los diferentes partidos; las mujeres criticaban, por primera vez, aspectos de la dinámica partidaria que aparecían como «naturales»: que mantuvieran económicamente a los maridos para que estos pudieran dedicarse a tiempo completo al partido y a la preparación de la revolución; que el partido no considerara los tiempos y ritmos diferentes de la actividad femenina, las múltiples jornadas, el cuidado en exclusividad de los hijos y del ámbito doméstico; el ser «reinas del mimeógrafo» antes que militantes con iguales deberes y derechos, etc. Estas comisiones que irrumpieron con fuerza en un primer momento quedaron, sin embargo, aisladas en los partidos como "asuntos de mujeres", sin lograr modificar, en lo sustancial, las dinámicas y las concepciones partidarias, porque"la estructura misma de los partidos de izquierda impidió el surgimiento de ese espacio, que integrara una forma de lo cotidiano en su militancia"2.

Se fueron así perfilando dos estilos de hacer política, dos miradas para entender la posición de las mujeres, dos perspectivas para orientar el cambio social. Como señala Julieta Kirkwood, este nuevo espacio recién descubierto que marcaba un enfoque diferente se convirtió en un espacio disputado, «peleado con airecillo de botín de vencedoras». Para las mujeres de partido la percepción dominante era que este espacio estaba lleno de mujeres pero vacío políticamente. Para las feministas autónomas sin embargo este espacio recién descubierto significaba el aprendizaje de un hacer político diferente ${ }^{3}$. Así y todo, durante un tiempo, diferenciándonos de las militantes de partidos pero influenciadas aún por los postulados de izquierda, tratamos de especificar nuestro feminismo: socialista, popular, revolucionario eran los apellidos que nos poníamos para hacer más digerible, para nosotras y para los partidos, nuestro compromiso y nuestra perspectiva feminista.

Comprendimos, sin embargo, varias cosas en este proceso: que el socialismo no tenía por qué ser solo privilegio de los partidos de izquierda; que el feminismo que postulábamos estaba comprometido con la imperiosa necesidad de justicia y demo-

2 Barrig, Maruja. Democracia emergente y movimiento de mujeres. En Movimientos sociales y democracia: la fundación de un nuevo orden. Eduardo Ballón (ed.) Desco. Lima. 1986.

3 Kirkwood, Julieta. Ser política en Chile. Las feministas y los partidos. FLACSO. Santiago de Chile. 1986. 
cracia; $y$, si queríamos extender el impacto de las ideas feministas en las mujeres y en la sociedad, esto sólo sería posible asumiendo la lucha por ampliar la democracia como un modo de vida y no solo como forma de gobierno. Cabe señalar que la democracia no era en ese momento una preocupación explícita de la mayoría de los partidos de izquierda, ni tampoco lo era la vida cotidiana. De allí hacia adelante, comenzamos a posicionarnos desde un feminismo "sin apellidos" aunque no por ello menos comprometido con la emancipación radical de las mujeres y de la sociedad. Las dos visiones se acentuaron. Las izquierdas partidarias continuaron analizando el movimiento de mujeres y sus demandas en base a ideas predeterminadas sobre lo que deberían ser sus acciones y su conciencia de mujeres, tendiendo a homogeneizarlas desde un enfoque clasista o economicista que analiza las acciones de lucha en términos más cuantitativos que cualitativos, definiendo el protagonismo de las mujeres, no como el proceso complejo, ambivalente, enriquecedor de búsquedas de nuevas y múltiples identidades, sino reducido a la capacidad de las mujeres de luchar contra el Estado, de apoyar las luchas generales, de responder a las necesidades familiares. Aunque estos aspectos están presentes en las prácticas de las mujeres, no son indudablemente ni los únicos ni los más libertarios.

Esta visión cuantitativa también ignoró el potencial de cambio de algunas vertientes del movimiento de mujeres o de otros movimientos, como él en ese momento naciente movimiento lésbico/homosexual, quienes se atrevieron a abrir un espacio hasta ese momento inexplorado, desde el cual cuestionar uno de los aspectos más reprimidos de la vida de los seres humanos, la sexualidad y su reduccionismo heteronormativo. Una y otra vez, a lo largo de esos años ( $y$, joh sorpresa!, aun ahora) la risa sarcástica frente a las feministas, la velada acusación de lesbianas o machonas y el abierto rechazo a asumir los derechos del cuerpo como parte de los derechos humanos y ciudadanos, nos hacía recordar que los partidos de izquierda eran, en estos temas, tan conservadores y autoritarios como todos los demás.

Nuestro alejamiento de los partidos de izquierda fue a todas luces beneficioso para el movimiento; aprendimos que es crucial para los movimientos sociales arriesgarse a vivir un «momento de escisión», como propone Gramsci, tomándose el tiempo para la introspección y para aislarse de las presiones e influencias de fuera, con el objetivo de poder construir un discurso propio y ganar autonomía ${ }^{4}$. Fue durante ese momento de «escisión» que se formaron los primeros grupos feministas de autoconciencia, los primeros colectivos temáticos y se inició un proceso de reflexión interpersonal de revisión crítica de todo nuestro bagaje político y cultural. Solo entonces pudimos generar nuevos entendimientos, nombrar lo que aun no tenía nombre, producir

4 Gramsci, Antonio. Notas sobre Machiavello: El Estado y la política. Análisis de situación y relaciones de fuerza. Juan Pablo Ed. México. 1988. 
teoría, desarrollar una perspectiva política feminista basada en nuestras múltiples realidades como mujeres y tomar distancia de la forma convencional de hacer política.

Con este bagaje y con clara afirmación de la autonomía, unos años después (1985), arriesgamos audazmente dos candidaturas feministas, en calidad de independientesno partidarias, en la lista de Izquierda Unida, que llevaba a Alfonso Barrantes a la presidencia de la república. No tuvimos éxito en ser elegidas (tampoco Barrantes, a pesar que se obtuvo un significativa votación), pero sí tuvimos éxito en la extraordinaria experiencia sobre los límites de la izquierda en relación a las mujeres ${ }^{5}$ y el enriquecedor conocimiento y complicidades con el movimiento urbano popular de mujeres en el país, una de cuyas expresiones más fascinantes en Lima fue María Elena Moyano y la Federación Popular de Mujeres de Villa El Salvador (FEPOMUVES).

En estos iniciales procesos, fueron las feministas chilenas en su larga lucha contra la dictadura de Pinochet las que nos dotaron de esa maravillosa consigna, levantada en marzo de 1983, y desplegada a lo largo de la Plaza Mayor de Santiago: Democracia en el país y en la casa. Con esta consigna, condensaban un posicionamiento en lo público que incorporaba la política de lo privado, en un terreno tan minado como el del Chile pinochetista, atravesando los límites de todas las democracias realmente existentes y no solo de su ausencia en dictaduras. Esta sola consigna expresaba una teoría radical de democracia y una forma transgresora de hacer política.

El asesinato de María Elena se dio muchos años después de estos procesos de escisión y autonomía (febrero 1992). En ese trágico momento me preguntaba: ¿Qué fue de esa izquierda que para las mujeres de mi generación significó quizá el único espacio en el que podíamos escapar del destino tradicional de las mujeres en el país, la única experiencia que nos permitía ser diferentes a nuestras madres, el espacio en el que nuestra rebeldía comenzó a perfilarse? ¿Qué pasó con esa izquierda de la cual nos sentimos parte tantos años, a pesar de nuestras diferencias y conflictos?

\section{Las dinámicas actuales}

Luego de casi cuatro décadas de nuestras primeras confrontaciones con nuestras izquierdas, y luego de casi veinticinco años del asesinato de María Elena, los contextos parecen haber cambiado, pero es asombroso constatar que, a pesar de los avances, no

5 Victoria Villanueva y Virginia Vargas fuimos las candidatas, en 1985. Habíamos participado activamente en la elaboración de la propuesta del Plan de Gobierno para las mujeres, pero nos dimos con la sorpresa que en el documento final, ya impreso, habían eliminado las referencias a la libre opción sexual y al derecho de las mujeres al aborto. Más aun, el día del acto final de cierre de campaña, estando en el estrado, Barrantes declaró abiertamente que estaba convencido que el problema de las mujeres era un problema de clase y no de su condición de mujer. Victoria y yo, en ese momento, bajamos del estrado y abandonamos el acto. 
siempre ha sido así, que las preguntas hechas en ese momento siguen siendo validas en los nuevos contextos. Son innumerables las reflexiones feministas que han ido surgiendo en todos estos años girando alrededor de esa misma realidad.

Una acotación fundamental, antes de continuar: hay una distorsión complaciente y poco democrática lleva a considerar en esta oleada a gobiernos como el de Daniel Ortega, de Nicaragua, denunciado por incesto por su hijastra Zoila America. Una alianza profunda con la jerarquía eclesiástica para evitar sanción moral, se expresó en la eliminación de ley de aborto más antigua de America Latina ${ }^{6}$ (1893), y persecución incansable a las feministas que lo denunciaron ${ }^{7}$. No solo a las feministas. Según Amnistía Internacional en su Informe de Derechos Humanos en 2012, evidencia que Ortega ha perseguido constantemente a los movimientos sociales, como lo refuerza la reacción de la prensa ante el informe

... que concentra el poder a toda costa; que aplica restricciones a los derechos políticos; que se muestra renuente para impulsar las reformas necesarias para la vuelta del sistema democrático; que se niega a abrir espacios a la sociedad civil; que busca desmontar a la ciudadanía desarrollando programas sociales que son meros paliativos frente a la pobreza que afecta a la mayoría de los nicaragüenses; la corrupción y finalmente la falta de voluntad de implementar las recomendaciones del Consejo de Derechos Humanos y otros órganos similares ${ }^{8}$.

En lo que sigue no pretendo analizar todos los países ni todas sus dinámicas, incluyentes o excluyentes, sino llamar la atención sobre algunas constantes en los procesos que muchas feministas están calificando como de re-patriarcalización.

\section{Las agendas feministas: justicia, derechos, democracia}

Indudablemente hay heterogeneidad en esta oleada progresista. En algunos casos, confrontando (al menos inicialmente y en algunas dimensiones) el modelo neoliberal (Venezuela, Bolivia, eventualmente Ecuador); otros gobiernos más complacientes con aquel (Brasil, Chile). Algunos con desarrollo más asentado de las reglas de convivencia democrática (Uruguay), o con democracias con menor desarrollo y mayor riesgo de

6 El artículo 165 del anterior Código Penal, en vigor desde 1893, permitía terminar un embarazo si tres o más médicos determinaban que la vida de la madre corría riesgo, si el embrión presentaba daños irreversibles o si el embarazo era resultado de un abuso o incesto.

7 Las denuncias sin embargo han seguido: se ha comprobad o que Ortega sostuvo una relación extramarital con una menor de 15 años en 2005, quien tuvo una hija no reconocida, que ahora tiene 4 años. Otra reciente denuncia evidencia nuevos hostigamientos sexuales

8 Miranda A. Wilfredo. "Se deterioran derechos civiles en Nicaragua"en Confidencial. 2012. En http://confidencial. com.ni/archivos/articulo/6854/se-deterioran-derechos-humanos-en-nicaragua 
autoritarismo (Paraguay en su momento, Venezuela). Hay gobiernos con democracias débiles pero que han implementado cambios significativos, al ser expresión de participación y gestión política de poblaciones quechuas y aymaras, históricamente excluidas del ejercicio de la política y que por lo mismo, con su sola presencia, la democratizan (Bolivia). Una primera distinción entre gobiernos de corte izquierdista radical y rupturista y gobiernos de corte más racional y gradualista, valida en los primeros años (y especialmente desde Venezuela de Chávez) parece no ser tan válida hoy, pues de alguna forma, todos ellos comienzan a tener una orientación económica similar.

En cada uno de estos países hay movimientos feministas diversos y activos. Mucho de lo avanzado ha sido posicionado y luchado por estos movimientos. Una constante está siendo las movilizaciones y campañas para posicionar las agendas más transgresoras, para estar atentas a las carencias que ahondan su exclusión, para modificar las visiones y acciones políticas hacia las mujeres, para expandir las democracias.

Los gobiernos, en sus inicios, avanzaron un conjunto de estrategias democráticas y participativas que entusiasmaron a los movimientos sociales. La adopción de nuevas categorías de análisis y de conflicto enriquecieron los términos de la conversación. Como es el caso de la Colonialidad del Poder (Aníbal Quijano), que ha dado origen no solo a nuevos horizontes de disputa y reconocimiento sino también han sido consagrada en Constituciones y en la institucionalidad estatal (Viceministerio de Decolonialidad en Bolivia). Muchas expresiones feministas han optado por incorporar en su ideario la disputa por la de-colonialidad del poder, del saber, del ser, alimentando perspectivas de interculturalidad. Nuevas miradas, desde cosmovisiones diversas, como el Buen Vivir, enriquecen también la reflexión hacia el cambio.

Ha habido sin duda ampliación de los espacios de participación política más activa de las mujeres. Sin embargo, los riesgos de cooptación o silenciamiento han comenzado a ser prácticas políticas que restringen su audibilidad. Muchas de las reflexiones feministas en el último período son elocuentes en señalar los logros y las carencias que colocan los contextos -más o menos democráticos- donde transcurre o ven limitado su accionar. Van de la mano con una mirada crítica que nos alerta sobre las limitaciones de los gobiernos en relación al modelo económico, en relación al tipo de democracia, en relación a la concepción del Estado y, por supuesto, en relación a la formas de hacer política desde y hacia las mujeres.

En casi todos estos países, el proceso de atender los derechos humanos y ciudadanos de las mujeres y de las diversidades sexuales ha sido arduo, desigual y riesgoso y ha dependido muchas veces de factores ajenos a la política democrática. Un ejemplo elocuente es el del presidente Tabaré Vásquez, de Uruguay —-país históricamente secular y con fuerte institucionalidad democrática-, quien, luego de entrevistarse con la jerarquía eclesiástica, objetó la propuesta de ley sobre despenalización del 
aborto, aprobada por amplia mayoría por el senado en su anterior gobierno. Esta acción coercitiva del estado desató una masiva acción política de solidaridad frente al procesamiento penal de una mujer que practicó un aborto. En un proceso asombrosamente acelerado, se produjo una politización radical que desafiaba el implícito "disciplinamiento colectivo" del Estado9. Todo este proceso reveló también nuevas formas de articular y expresar ciudadanía. La campaña tuvo su punto máximo al entregar al Vicepresidente de la República nueve mil firmas de "delincuentes autoinculpados". Con estas nueve mil firmas en cuatro semanas se logró modificar la correlación de fuerzas, convirtiendo, como dice el título del artículo analítico de la campaña, un derecho carente de sujeto relevante, a un sujeto político democrático.

\section{a. ¿Oleada de izquierda u oleada progresista?}

Si bien no todos los países confrontan la idea del desarrollo capitalista en sus vicios actuales, todos dicen orientarse hacia políticas de redistribución y reconocimiento. Varios países, especialmente los andinos, en sus enunciados inciales confrontaban la idea de desarrollo para ofrecer pistas alternativas surgidas de otros saberes y cosmovisiones, como por ejemplo la idea del Buen Vivir, incorporado en las Constituciones de Ecuador y Bolivia. Hoy, la idea de Buen Vivir parece estar formateándose para hacerla mas afín a la lógica desarrollista convencional que estarían aplicando ${ }^{10}$.

Asi, la disputa sobre los modelos de desarrollo cobra enorme importancia por aquello que prometían y que no se dio. Son experiencias /propuestas post-neoliberales, porque rompen algunas de las dimensiones centrales del modelo, como la consolidación de un Estado fuerte que orienta las decisiones económicas y políticas de integración y redistribución. Sin embargo, no es suficiente. Una distinción interesante sobre las características de estos gobiernos la ofrece Gudynas, al diferenciar izquierda y progresismo. Los gobiernos son progresistas porque han dejado caer muchas ideas fuerza y núcleos centrales de prácticas socialistas, libertarias, democrática o emacipatorias: son gobiernos que se alejan de consultas ciudadanas o de una participación activa para enfocarse en mecanismos electorales clásicos, debilitando el protagonismo político de quienes los llevaron al poder, distanciándose de movimientos indígenas ambientalistas, feministas, de derechos humanos. Reduciendo la justicia a la redistribución económica y no al cambio de matriz estructural. Y asumiendo como

9 Sanseviero, Rafael. "El blog 'Yo aborté' en Uruguay. Análisis de prácticas feministas". 2007. En http://www. mujeresdelsur.org.uy/asamblea07/blog_aborto.pdf

10 Gudynas, Ernesto. "Extractivismo, gobiernos "progresistas” y alternativas del Buen Vivir". En: Rebelión. 2015. En: http://www.rebelion.org/noticia.php?id=196326

\section{6/ REVISTA DESOCIOLOGGía 26}


modalidad central el modelo exportador primario, ya sea en minería, agro negocios o (neo) extractivismo exportador ${ }^{11}$.

Esta política (neo) extractivista e invasora de las tierras ancestrales y de ecosistemas, es la que ha generado las mayores confrontaciones: TIPNIS en Bolivia, Yasuni en Ecuador, Bello Monte y varias otras en Brasil (que además de sus políticas extractivista, ha desarrollado un sinnúmero de proyectos de infraestructura y de exploración de recursos naturales en regiones transfronterizas y en otros diversos países en la región). Incluso, en Uruguay, donde según afirma Daniel Pereira, en los últimos años el gobierno ha adoptado un conjunto de medidas con el objetivo de fomentar la explotación minera por parte de empresas extranjeras; se ha cambiado legislación, facilitando la explotación a cielo abierto ${ }^{12}$. En relación a Venezuela, Edgardo Lander nos ofrece un análisis que es generalizable a estas otras realidades: Venezuela evidencia que el extractivismo rentista no solo produce petróleo, sino que conforma un modelo de organización de la sociedad, un tipo de estado, un régimen político, unos patrones culturales y unas subjetividades e imaginarios colectivos... difícilmente revertibles luego de pasar la etapa extractivista ${ }^{13}$.

Los impactos del neoextractivismo en la ecología, en los territorios comunales, en el ecosistema, en las vidas cotidianas y los cuerpos de las mujeres son enormes. Ha alimentado múltiples formas de violencia social: creciente violencia contra la mujer, trata, alcoholismo, prostitución, mercantilización, conflictos entre e intercomunales por los impactos territoriales de estas incursiones, etc. Para todo esto, y mucho mas no existen políticas adecuadas, y no hay interés (salvo Uruguay) en una política y una economía de "cuidado", dimensión clave para buscar el cuidado de la naturaleza además del cuidado de nuestros cuerpos. Esto es más que redistribución paritaria de las responsabilidades y cargas de trabajo en lo privado, pues su implementación requiere otra perspectiva, otro enfoque económico, otra forma de pensar y actuar, que ve el objetivo de la acción política no en la maximización del beneficio económico, sino la realización de los intereses vitales del ser humano. Esta dimensión ha sido un aporte feminista que ha enriquecido la reflexión sobre el Buen Vivir para las mujeres

11 Gudynas, Eduardo. "10 tesis sobre el 'divorcio' entre izquierda y progresismo en América Latina". En: Ideas, suplemento de página 7, La Paz, 2014.

12 Daniel S. Pereira. "Una mirada desde el Sur. Balance crítico del gobierno de Mujica". En www.revistapueblos. org/?p=15760.

13 Lander, Edgardo. “¿Crisis Terminal del modelo petrolero rentista?". En Aporrea. 2014 En: https://www.aporrea. org/actualidad/a197498.html Para Lander, no es solo una orientación de los gobiernos progresistas, sino que "se trata de un modelo productivo que forma parte de concepciones compartidas entre los países del ALBA, como lo evidencia la declaración de Alba, 2013, que habla del potencial de los recursos no renovables para el financiamiento del desarrollo [...] rechazando la posición extremista de algunos grupos que se oponen a la explotación de los recursos naturale... y exigen consulta previa". 


\section{b. Los desfases democráticos}

En las últimas décadas, el horizonte de "merecimiento" de derechos se ha ampliado en las sociedades latinoamericanas. Nuevas voces, nuevas problemáticas sexuales, étnicas, raciales, generacionales, han sido posicionadas en lo público, enriqueciendo la trama de diversidad social. Esta nueva subjetividad de merecimiento es una ganancia democrática y es una señal para orientar la política estatal y políticas públicas, consolidando la institucionalidad que protege los derechos humanos y ciudadanos. Sin embargo, suelen haber errores debilitadores de la democracia, de lo ganado y lo exigido por estas nuevas subjetividades. Son errores antidemocráticos.

El ejercicio democrático de los gobiernos varía, siendo Uruguay quizá el más amplio en su horizonte de derechos. Existe, en diferentes dosis, una especie de autoritarismo que ha criminalizado en diferentes momentos la protesta o que fácilmente acusa a opositores de terroristas o imperialistas. Es llamativa la creciente tendencia al hiperpresidencialismo, o, como señala Guillermo O’Donnell, a la preeminencia de democracias delegativas, que él define como regímenes centrados en la persona, dominando todos los poderes, debilitando los controles democráticos y colocando la lealtad al gobierno político como lo central ${ }^{14}$. Es interesante notar que la absoluta mayoría de los intentos de alargar su presencia en el poder lo realizan los gobiernos progresistas. Y aunque, en algunos casos, no lo lograron, como el reciente referéndum en Bolivia que dijo No a la reelección de Evo (o como anteriormente en Ecuador), queda en el imaginario estatal el "derecho" —inexistente en democracia — a su permanencia en el poder. Existen también probados casos de corrupción.

Hay también errores antidemocráticos en los cálculos y negociaciones políticas. Es el caso de Brasil, ad portas hoy de un golpe de estado parlamentario y corrupto, absolutamente injustificable, en donde alianzas previas propiciaron este embate conservador. En 2013, en una visita al parlamento en Brasilia, las parlamentarias del PT que pude entrevistar, evidenciaron que el PT había negociado para si algunas de las comisiones parlamentarias de "mayor" peso político y económico (Finanzas, Comercio...) dejando en manos de la bancada evangélica interpartidaria (la misma que hoy quiere defenestrar a Dilma Rousseff) la Comisión de Derechos Humanos. Fue tal su arremetida contra los derechos humanos y particularmente los derechos de las mujeres que las feministas del PT y aliadas organizaron una Comisión de Derechos Humanos paralela, con voz en el senado, para evitar su avance.

En varios países ha habido nuevas Constituciones, que han consagrado mayor igualdad. Hay dos Estados Plurinacionales, que ayudan a romper el mito de la"nación"

14 O’Donnell Guillermo. “Democracia Delegativa”. En La Nación. 2009.

\section{8/ REVISTA DESOCIOLOGÍA 26}


unitaria sobre la que se construyó el imaginario estatal. Si bien han ampliado la perspectiva del "nosotros", al mismo tiempo parecen estar acotándolo a las comunidades leales y distanciando o reprimiendo a las acciones y organizaciones críticas. Una pregunta constante para las mujeres es como armonizar las diversas normatividades sobre las mujeres al mismo tiempo que se trabaja en una noción de "derechos" que sea referente a diversas culturas, para construir desde allí mirada intercultural.

Estos desfases estarían evidenciando, según Norbert Lechner, "una falta de adecuación de la política y del estado a los cambios estructurales que están viviendo las sociedades... lo que es también una concepción tradicional de lo que es y lo que puede hacer la política"15.

\section{c. Las actoras in situ: resistiendo la re-patriarcalización}

Las reflexiones feministas recientes sobre las izquierdas/progresismos son elocuentes en señalar las carencias en relación no solo a las mujeres sino a la forma de concebir y actuar la política y la democracia. Nos dan un piso para un mejor entendimiento de los retos enfrentados por las mujeres.

Beatriz Gimeno en base a su experiencia militante en partidos de izquierda señala que mientras la autoridad feminista es permanentemente negada, fragilizada y cuestionada, la de aquellos que cuestionan el feminismo nunca les es retirada. Cuestionar el feminismo no pasa factura en un partido pero ser feminista todo el tiempo sí. Al mismo tiempo, confronta "... esa mirada masculina que no se cuestiona, que pone al hombre como centro y medida de todas las cosas, (que) es devastadora para las feministas en política. Es la que hace que para cualquier partido político sea mucho más importante, por ejemplo, una ley de represión política o ciudadana que una ley de represión del cuerpo..."16.

También en el XI Encuentro Feminista Latinoamericano y del Caribe(EFLAC) de 2009 en México, muchas feministas confluyeron en un espacio de reflexión sobre las izquierdas, buscando recuperar la memoria y analizar los posibles cambios. El documento que salió de este espacio fue muy expresivo de lo que se experimentaba como constante en la mirada de las izquierdas:

Quienes levantamos el acta de agravios somos feministas del siglo XXI, mujeres diferentes a las que fuimos pero también las mismas de siempre, porque siempre creímos en una izquierda democrática que busca la justicia social. Y lo hacemos

15 Lechner, Norbert. "Las condiciones de gobernabilidad democrática en la América Latina de fin de siglo". En Sociedad y política. Buenos Aires: Flacso. 1987

16 Gimeno, Beatriz. "Ser feminista en un partido político (mi experiencia)". En: Pikara. 2014. En: http://www.pikaramagazine.com/2014/05 
desde nuestras concepciones feministas sobre la izquierda y la democracia que defendemos; desde la conciencia de haber aportado nuestro esfuerzo y nuestro ideario al cambio social y político; desde la autoridad de haberlo dado todo para que la izquierda llegase al poder y desde la bronca de que tantas veces se hayan traicionado nuestras expectativas... En la última década hemos probado los sinsabores de tener que negociar con las izquierdas en el gobierno. Hemos tenido éxitos pero también sonadas derrotas. Y estas casi siempre han tenido que ver con los derechos sexuales y reproductivos, la diversidad sexual, la paridad, la laicidad. Estamos en condiciones de identificar los muros con los que siempre topamos cada vez que exigimos a los partidos de izquierda que cumplan sus promesas, que sean coherentes con sus postulados de justicia, igualdad y libertad ${ }^{17}$.

Un acercamiento a algunos países (los andinos) nos puede dar una idea más apropiada de las complejidades que presenta el reconocimiento de la condición de sujeto político que proponen los feminismos.

El caso de Venezuela, en el período de Chávez, es interesante. Es innegable que la Revolución Bolivariana ha traído mejoras para todo el pueblo venezolano, especialmente para las mujeres ${ }^{18}$. Es también donde el feminismo socialista parece tener más desarrollo. En el Programa de transición al socialismo y de radicalización de la democracia participativa y protagónica, las feministas han aportado a cada uno de los ejes programáticos, afirmando en ellos que la erradicación del patriarcado es parte integral de la lucha contra el capitalismo y que no es posible construir una sociedad socialista, sin feminismo.

Chávez en repetidas ocasiones dirigió su discurso a la defensa de los derechos de las mujeres, a la crítica al machismo, declarándose el mismo un "feminista socialista convencido"; sin abandonar sin embargo su lenguaje confrontacional y en muchas formas, tradicional: "Los socialistas deben ser feministas o no serán seres humanos completos. Con el apoyo de nuestras mujeres debemos fortalecer la unidad de Venezuela y así podremos fortificar los elementos para convertir a este país en una potencia"19.

Sin embargo, no ha habido avances en el tema de aborto, ni en el matrimonio/ unión del mismo sexo. Una de las opiniones últimas de Chávez en relación al aborto terapéutico es contundente: declaró que no solo era conservador en este punto,

17 Las Feministas y los partidos de izquierda en el gobierno. Taller realizado en el XI Encuentro Feminista Latinoamericano y de El Caribe. México, D.F., 18 y 19 de marzo de 2009

18 Las Misiones Sociales, la aprobación de la Ley Orgánica sobre el Derecho de las Mujeres a una Vida Libre de Violencia, la Ley de Promoción y Protección de la Lactancia Materna, la creación de la Comisión Nacional de Justicia de Género, y el Ministerio del Poder Popular para la Mujer y la Igualdad de Género así lo indican.

19 Declaraciones tomadas de: Pineda, Esther. "Las mujeres en la revolución bolivariana”. 2009 En: https://estherpinedag.wordpress.com/2013/02/09/las-mujeres-en-la-revolucion-bolivariana/

\section{0/ REVISTA de SOCIOLOGǴA 26}


sino totalmente contrario. En relación a la unión/matrimonio ahí su postura fue más flexible: "No lo vemos bien, pero es solo un estado de opinión". Algunos políticos encuentran explicación en el hecho que se trata de asuntos propios de sociedades más estable y en Venezuela resultan temas menores, debido al peso de temas más gruesos como inflación, desempleo, ideología, democracia. Así y todo, las voces feministas desde el interior del gobierno y desde lo movimientos más autónomos y opositores llevan una permanente lucha por el reconocimiento del aborto como derecho de las mujeres ${ }^{20}$. Nicolás Maduro llamó recientemente a debatir sobre el aborto, sin ninguna respuesta. En esto sí es más o menos evidente que en la tremenda crisis que está viviendo ese país el posicionamiento alrededor del aborto tendrá un escenario muy poco favorable.

Otros dos países, Ecuador y Bolivia, expresan un intrincado y ambivalente posicionamiento e intervención en relación a los derechos de las mujeres, en contextos de debilitamiento de la democracia.

En Ecuador, la Constitución de 2008 contiene tremendos avances en materia de derechos ecológicos, económicos, sociales, de género, de orientación democrática, etc. El apoyo con el que Rafael Correa llegó al gobierno fue grande y sigue teniendo importante apoyo. La Revolución Ciudadana inició reformas políticas, económicas, sociales, educativas, etc. buscando aplicar una forma de "socialismo" en Ecuador. Sin embargo últimamente se ha notado un desgaste acelerado de Alianza País y la Revolución Ciudadana, al haber acumulado un conjunto de medidas excluyentes y autoritarias. El primer paro nacional y levantamiento indígena, de agosto $2015^{21}$, alertó sobre el cambio de la matriz energética y productiva, denunció el "proyecto político-económico modernizador capitalista, de corte conservador, y afirmó su lucha contra el extractivismo y en defensa de los territorios ${ }^{22}$. Esta política extractivista neo desarrollista contraviene dramáticamente los mandatos constitucionales que afirman los derechos de la naturaleza, la economía organizada alrededor del ser humano, la prohibición de uso de transgénicos, la soberanía alimentaria, etc. En el campo laboral, la reforma propuesta, según los sindicaros, atenta contra los derechos laborales y especialmente en su derecho de organización y de huelga.

20 En la Jornada Saca los Trapitos al Sol, contra la violencia patriarcal y capitalista, organizado por las feministas socialistas del colectivo La Araña y de muchos otros, han puesto permanentemente en el debate público la reflexión en torno al aborto o interrupción libre y voluntaria del embarazo.

21 Antes, en 2013 y 2013 hubo movilizaciones de protesta pero esta ha sido la más contundente.

22 Daza, Esteban y Santillana, Alejandra. "Movilizaciones en Ecuador: cambio de ciclo y perspectivas críticas. Pensamiento Crítico". En: Línea de Fuego. 2015. En: Daza, Esteban y Santillana, Alejandra. 2015. “Movilizaciones en Ecuador: cambio de ciclo y perspectivas críticas. Pensamiento Crítico". En Línea de Fuego. En: https://lalineadefuego.info/2015/09/22/movilizaciones-en-ecuador-cambio-de-ciclo-y-perspectivas-criticas-por-estebandaza1-y-alejandra-santillana2/ 
Esta nueva orientación del gobierno ha significado una limitación drástica de la participación ciudadana, con el argumento que el estado posneoliberal es un estado poscorporativo (argumento similar en el gobierno de Bolivia). En esta visión, la protesta es judicializada porque desestabiliza al régimen, traiciona la patria, practica el sabotaje. De allí el creciente deterioro de la relación con los movimientos sociales al avanzar en una dinámica de reducción de los derechos contemplados en la constitución (además del control en las universidades y en los medios de comunicación). En este contexto de deterioro democrático, las política patriarcales son evidentes: desde un discurso moralista, confesional y misógino, propone prevenir el embarazo adolescente con valores morales y con abstinencia, penaliza a jóvenes que tienen relaciones sexuales antes del matrimonio. Impulsa políticas de fortalecimiento de la familia y de transverzalización de la perspectiva familiar. Ha habido retrocesos en el programa de salud sexual y reproductiva, en prevención del Sida, en educación sexual como una forma de restar relevancia a los derechos de las mujeres y sustituir la perspectiva de género ${ }^{23}$. Ha desaparecido también la institucionalidad de género en el Estado (CONAMU), reemplazándola por una oficina que está a cargo de una militante del Opus Dei.

El caso de la despenalización del aborto en caso de violación es un ejemplo claro de esta re-patriarcalización: Amenazando en dimitir como presidente si se discutía el aborto, acusando de traición a las feministas parlamentarias de su partido que lo propusieron, amenazadas con expulsión y castigadas con cura de silencio. Por eso, Margarita Aguinaga señala que está surgiendo un nuevo patriarcado, que "supone mantener el dominio de las mujeres por medio del Estado, la religión, la cultura, etc. fortaleciendo una lógica de autoritarismos que también se reproduce a nivel de funcionarios y funcionarias del Estado"24. Y expresando, además, un tremendo desprecio por las mujeres (indígenas, jóvenes, las que no callan, las que confrontan, las que se visten como les da la gana), como lo expresan sus chistes y opiniones sobre estas mujeres:

Qué asambleístas que tenemos guapísimas ahh, eh Corcho hay que aumentarles el sueldo eh porque no tuvieron plata para comprar suficiente tela y todas con unas minifaldas Dios mío, (risas). Yo ni me fijo en esas cosas me contaron, me contaron unas piernas y unas minifaldas impresionantes guapísimas las asambleístas... ${ }^{25}$

23 Monroy, Lilian. Ecuador con Correa. Quito: Ed. Limón. 2010.

24 Aguinaga, Alba Margarita. Análisis feminista de coyuntura del gobierno de Rafael Correa y la dinámica política del movimiento de mujeres y feminista, 2010- 2012. Quito: UCE. 2013.

Declaraciones de Rafael Correa en el año 2011.

\section{2/ REVISTA DESSOCOLOGGíA 26}


En otra oportunidad dirá:

¿Me van a decir conservador por creer en la familia? Bueno, yo creo en la familia. Y creo que esta ideología de género, estas novelerías, destruyen la familia convencional, que sigue siendo, que seguirá siendo la base de nuestra sociedad ${ }^{26}$.

El caso de Bolivia es más ambivalente, porque al mismo tiempo que avanza en propuestas democráticas para las mujeres, no resiste las tendencias a la re-patriarcalización. Sus ventajas han sido el ser el primer gobierno liderado por un presidente campesino-indígena en la región, lo que ha tenido un impacto simbólico significativo, no solo en Bolivia, sino en los países andinos y el conjunto de la región. En sus hasta ahora 10 años de gobierno ha habido avances sustantivos en muchos planos: la pobreza se redujo de $38.2 \%$ a $17 \%$, el sueldo mínimo subió hasta $127 \%$, entregó títulos de tierras, mayor presupuesto a la educación, asistencia a mujeres embarazadas, etc. La Asamblea Constituyente aprobó, en 2008, la nueva constitución, amplia, inclusiva, plurinacional, ecológica, con claros contenidos feministas: paridad y alternancia, equidad de género, orientación sexual, idioma, religión, ideología, filiación política, embarazo, nacionalidad; no a la violencia hacia la mujer en todas sus formas, reconocimiento del valor del trabajo doméstico, etc.

Avanzar de las cuotas a la paridad ha sido una ganancia que tiene, sin duda, impacto en el imaginario de derechos de las mujeres y en el imaginario democrático. La diferencia entre cuota y paridad es una diferencia sobre la comprensión de la democracia, porque la paridad no plantea la compensación de una injusticia (como lo hacen las cuotas) sino una manera de comprender y de funcionar la democracia. Es incorporar la diferencia sexual al concepto mismo de democracia. Sin embargo, la realidad tenazmente se impone a los contenidos institucionales democráticos. Según datos de la ONU, Bolivia es el país con más violencia machista en America Latina; la nueva ley ha permitido aumentar las denuncias pero no disuadir a los hombres de ser violentos. Esto lleva a Javier Aliaga y Lorena Canto a afirmar que "... la década económica dorada que ha vivido Bolivia con Evo Morales cojea en avances sociales, con un estado de derecho minado por la crisis de la justicia, los altos índices de violencia machista y contra la infancia, el legalizado trabajo infantil y la deficiente sanidad"27. Ello se evidencia a través de inesperados escándalos sobre hijos e hijas no reconocidos por el Presidente o en el "oscuro" incidente de la ex pareja de Morales, implicada en un escándalo de tráfico de influencias, desde el gobierno, a través de una empresa

26 Comentario de Rafael Correa, emitido en diciembre de 2013.

27 Aliega, Javier y Cantó, Lorena. "Evo Moral, una década de gobierno con menos pobreza y más corrupción". En: El Nuevo Herald. 2016. En: http://www.elnuevoherald.com/noticias/mundo/america-latina/article55945275. html 
proveedora del Estado ${ }^{28}$. Estos incidentes dejan antecedentes nefastos sobre el uso y mal uso de las leyes de acoso sexual, de acoso político, de reconocimiento de las responsabilidades paternales.

Las dificultades de acceso a la justicia, que aparentemente se da en todos los niveles, en el caso de las mujeres son más lentas e ineficaces muchas veces para sus demandas y para atender los nuevos riesgos que enfrentan. Sin duda una ganancia para toda la región ha sido la ley de Acoso Político que impulsaron las feministas bolivianas, evidenciando una dimensión de violencia novísima por el espacio en que se ejerce: el espacio institucional. Indudablemente ha existido antes, pero en mucho menor escala - y sin tanta soberbia y crueldad — quizá porque no eran muchas las mujeres autoridades. Ahora, la mayor presencia de mujeres en política provoca los intentos de los hombres políticos de expulsarlas de este espacio y "arrebatarles un derecho adquirido". Ante las primeras denuncias, fue evidente que existía un vacío jurídico pues esta violencia no estaba contemplada como delito. Al nombrarla, lo volvieron hecho político. La campaña por la ley se inició en 2001 y solo fue aprobada en $2012^{29}$. ¡Demoró 11 años! Lo que, dramáticamente, aceleró su aprobación fue el asesinato - después de una larga batalla legal para recuperar el ejercicio de su cargo — de la concejala Juana Quispe, del distrito de Ancoraimes, en La Paz. Hoy, la lucha por la aprobación de la ley de acoso político se está dando en numerosos países de la región, siendo ya aprobada en Perú, México y Argentina.

Las diferentes expresiones feministas en Bolivia han sido también impactadas por estos procesos. El creciente autoritarismo del gobierno, unido al permanente irrespeto de Evo (y el MAS) en relación a las mujeres han sido una especie de parteaguas en el movimiento feminista. Un sector significativo cuestiona y critica. Otro sector apoya, tanto a las feministas que están en el MAS como colectivos del feminismo comunitario (Mujeres Creando-Comunidad), con una propuesta interesante como feministas comunitarias, su apoyo a Evo se da por ser un presidente campesino-indígena, cuya presencia y gobierno permitirá superar el racismo, aunque están conscientes que el Estado sigue siendo colonial, patriarcal, neoliberal. Otros colectivos feministas, como Mujeres Creando son de particular importancia y visibilidad, con fuertes críticas al gobierno de Evo, porque la Constitución del 2009 dejó intacto el patriarcado, las fuerzas armadas y la Iglesia. Un aporte significativo de María Galindo fue el confrontar el contenido patriarcal de los procesos de descolonización impulsados por el gobierno

28 Asimismo, hay un hijo adicional no reconocido previamente, de quien se afirma que está muerto pero todos los indicios apuntan a lo contrario.

29 El documento de ley dispone que la norma será aplicable a mujeres en cargos públicos comprendidos desde la Presidencia de la República, Vicepresidencia, Asambleístas, Senadoras, Diputadas, Alcaldesas, Concejalas, Agentes municipales, Prefectas Consejeras departamentales o integrantes de la directiva de cualquier instancia que la haya elegido democráticamente y que sean víctimas de acoso o violencia política. 
desde el Vice Ministerio de Descolonización, al no considerar los derechos de las mujeres ni de las diversidades sexuales. La consigna lanzada, de gran contenido político feminista, fue: sin despatriarcalización no hay descolonización. El gobierno asumió el reto, formando una Oficina de Despatriarcalización dentro del Viceministerio, cuyo contenido y orientación sin embargo ni de lejos recupera los contenidos originarios y transgresores, según Galindo.

Quizá la más desagradable expresión pública patriarcal es la que lleva adelante el presidente junto con algunos hombres y algunas mujeres del MAS a través de los chistes y canciones misoginias, devaluadoras de las mujeres. Sus contenidos van más allá de "bromear"y ridiculizar los cuerpos de las mujeres. También impulsan una complicidad con el irrespeto y la violencia hacia las mujeres, incitando a ser usadas y vejadas a nombre de los intereses de la política gubernamental:

Si yo tuviera tiempo, "iría a enamorar a las compañeras y convencerlas de que no se opongan". Así que, jóvenes: tienen instrucciones del Presidente de conquistar a las compañeras yuracarés trinitarias [indígenas amazónicas de Bolivia] para que no se opongan a la construcción del camino ${ }^{30}$.

\title{
III. Finalmente....
}

\begin{abstract}
¿Con quiénes estamos arreglando cuentas? ¿Con una izquierda que fue pero ya no es tal, para nuestro asombro y desconcierto? ¿Con una izquierda que nunca fue, aunque no lo sabíamos entonces... o lo sospechábamos, pero no lo queríamos creer? ¿Con una izquierda que era poco izquierda, pero era "nuestra" izquierda? ¿Con una izquierda a la que creímos cuando nos dijo que"solo ella y su revolución abrirían las puertas" a nuestras justas reivindicaciones y que más nos valía andar bien pegaditas a ellos? ¿Con una izquierda que nunca volverá, un amor de juventud, porque los tiempos han cambiado y nosotras también? ¿Con una izquierda que nos coloca en las tierras movedizas del populismo y el clientelismo? ¿Con una izquierda que nos expulsa de la casa común si la criticamos, cual mala madre que nos arroja a la orfandad? ${ }^{31}$
\end{abstract}

Estos gobiernos de izquierda/progresistas han contribuido en atender las formas más tenaces de injusticia, a redistribuir la riqueza, en avanzar reformas políticas y económicas, a visibilizar nuevos sujetos políticos, a ampliar ciudadanía. Sin embargo, los cambios que remuevan injusticias y exclusiones, para su permanencia, requieren de cambios culturales y contraculturales, que modifiquen los sentidos comunes tra-

30 Declaraciones de Evo Morales el 31 de julio de 2011, en concentración pública en Cochabamba.

31 Las Feministas y los partidos de izquierda en el gobierno. Op. Cit. 
dicionales sobre las mujeres y las diversidades, que alimenten nuevas miradas, que democraticen las vidas cotidianas. Estas dimensiones parecen no estar hoy presentes en los idearios de las izquierdas/progresismos en el poder. Muchas de las experiencias de estos gobiernos no han sido ni suficientemente inclusivas, ni suficientemente democráticas, ni suficientemente sensibles como para que no sigan repitiendo algunas de las falacias y autoritarismos de su historia.

También es evidente la arremetida conservadora en la región. Muy cercana aparece la experiencia de Paraguay con el "golpe blanco" contra Lugo (previamente, en Honduras), que pretende ser reeditado en este momento en Brasil, con los intentos de destitución a Dilma, grotescamente justificados "a nombre de Dios y la familia", al mismo tiempo que felicitan a su torturador. Los intentos exitosos de desestabilización de Venezuela, frente al débil gobierno de Maduro, con poca capacidad política para enfrentar una crisis, no solo política sino económica (producida además en parte por la política extractivista y petrolera que alimentó el proceso bolivariano en la primera década del gobierno de Chávez). El triunfo de Macri en Argentina, junto con la creciente conflictividad en Ecuador y en Bolivia, dejan muchos interrogantes sobre hacia adonde avanzar.

Estos problemas se agudizan frente al irrespeto de la autonomía de los movimientos, a reconocerlos solo cuando apoyan a los gobiernos, mientras que los criminalizan cuando levantan voces críticas. En el caso de las mujeres, los avances en leyes, reconocimientos ciudadanos, paridad, se ven empañados por las enormes dificultades de asumir los derechos del cuerpo. En este momento, solo Uruguay, en el período del presidente Mujica, y recientemente Michelle Bachelet en Chile, han despenalizado el aborto (por tres causales: peligro de vida de la madre, malformación fetal y violación) y han legalizado la unión civil entre personas del mismo sexo. Esto nos coloca de lleno frente a varias de las dimensiones menos asumidas por los gobiernos: la ampliación de los alcances democráticos a dimensiones privadas de alto contenido político, la urgente modificación del Estado "tutelar" y la defensa del carácter laico de los Estados como condición fundamental de una democracia plural.

Sin embargo, comienzan a verse otras dinámicas en el horizonte. Hay intensos proceso de crítica a la falta de democracia en los partidos políticos, a su forma de relacionarse con los movimientos sociales, a la forma en que detentan y organizan el poder. Parecería estar surgiendo izquierdas democráticas, audaces, interseccionales y articuladoras, como lo expresa toda la experiencia zapatista y neo zapatista, cuya consigna "mandar obedeciendo" expresa sin duda otra forma de pensar y actuar la política y el poder, además de la enorme riqueza de un feminismo propio desarrollado por las mujeres zapatistas. Más aun, en las últimas elecciones presidenciales en Perú, el Frente Amplio, claramente de izquierda, alcanzó un significativo tercer lugar en

\section{6/ REVISTA DESSOCOLOGGíA 26}


las elecciones y se convierte así en un nuevo y contundente actor político, con Verónika Mendoza, cuya forma de hacer política es no solo refrescante sino que levanta aquellas dimensiones generalmente negadas por las izquierdas: la subjetividad, las emociones, la afirmación de los lenguajes desvalorizados como dialectos (inicia en quechua todas sus presentaciones), el derecho al aborto, la unión civil, además de la revalorización de las culturas y cosmovisiones andinas, además de un claro posicionamiento en contra del extractivismo sin control, y buscando recuperar la idea que la democracia electoral es importante, sin duda, pero no es el único medio democrático para impulsar cambios ${ }^{32}$ : la desobediencia civil, el derecho a la rebelión, a tomar la palabra, a seguir siendo actoras y actores de los cambios emancipatorios. Ello indudablemente trae esperanzas. A pesar que la historia previa y en muchos casos, muy reciente, no promete mucha democracia.

\section{Referencias bibliográficas}

AgUINAGA, Alba Margarita (2013). Análisis feminista de coyuntura del gobierno de Rafael Correa y la dinámica política del movimiento de mujeres y feminista, 2010-2012. Quito: UCE.

ARDITTI, Benjamín (2009). “El Giro a la Izquierda en America Latina: ¿una política post-liberal?” En Ciencias Sociales Unisimos. vol. 45.

BARRIG, Maruja (1986).“Democracia Emergente y Movimiento de Mujeres”. En Eduardo Ballón (ed.). Movimientos Sociales y democracia: I fundación de un nuevo orden. Lima: DESCO.

DazA, Esteban y SANTILlana, Alejandra (2015). "Movilizaciones en Ecuador: cambio de ciclo y perspectivas críticas. Pensamiento Crítico". En Línea de Fuego. En: https://lalineadefuego. info/2015/09/22/movilizaciones-en-ecuador-cambio-de-ciclo-y-perspectivas-criticaspor-esteban-daza1-y-alejandra-santillana2/

Gimeno, Beatriz (2014). "Ser feminista en un partido político (mi experiencia)". En Pikara. En: http://www.pikaramagazine.com/2014/05

GRAMSCI, Antonio (1988). Notas sobre Machiavello: El Estado y la política. Análisis de situación y relaciones de fuerza. Mexico: Juan Pablo Ed.

GUDYNAS, Eduardo (2014)."10 tesis sobre el'divorcio' entre izquierda y progresismo en América Latina". En Ideas, suplemento de página 7. Domingo 079 de febrero.

KIRKWOOD, Julieta (1986). Las feministas y los partidos de izquierda en el gobierno. Santiago de Chile: FLACSO.

LANDER, Edgardo (2014). "¿Crisis Terminal del modelo petrolero rentista?". En Aporrea. En: https://www.aporrea.org/actualidad/a197498.html

32 Arditti, Benjamín. "El Giro a la Izquierda en America Latina: ¿una política post-liberal?" En Ciencias Sociales Unisimos. vol. 45. 2009. 
LECHNER, Norbert (1987). “Las condiciones de gobernabilidad democrática en la América Latina de fin de siglo". En Sociedad y política. Buenos Aires: FLACSO.

Miranda A., Wilfredo (2012). "Se deterioran derechos civiles en Nicaragua". En Confidencial. En: http://confidencial.com.ni/archivos/articulo/6854/se-deterioran-derechos-humanos-en-nicaragua

MonRoy, Lilian (2010). Ecuador con Correa. Ed. Limón.

O’DonnelL, Guillermo (2009). “Democracia Delegativa”. En La Nación, 04 de diciembre.

SANSEVIERO, Rafael. 2007. "El blog 'Yo aborté' en Uruguay. Análisis de prácticas feministas". En http://www.mujeresdelsur.org.uy/asamblea07/blog_aborto.pdf

VARGAS, Virginia (2008). "Feminismo e izquierda en el Perú: Trágicos desencuentros". En: Feminismos en América Latina. Su aporte a la política y a la democracia. Lima: UNMSM, PDTG, Flora Tristán. 